\title{
Contribuição epistemológica do regime militar ao campo jornalístico: a monografia da imprensa brasileira elaborada pelo SNI ${ }^{1}$
} Álvaro Nunes Larangeira

\section{Resumo}

A partir das informações dos principais jornais em todos os Estados do Brasil colhidas pelas sucursais do Serviço Nacional de Informações, em documentação encontrada no Fundo SNI do Arquivo

Nacional, 0 artigo concebe uma monografia da imprensa brasileira, enfatizando confluências, desvios e divergências entre empresas de comunicação e governo militar, na intenção de contribuir com os estudos da memória jornalística no período do regime militar e amplificar os sítios de pesquisa de expressão nacional da História da Comunicação no Brasil, comumente restritos às regiões Sudeste e Sul do país.

\section{Palavras-Chave}

Imprensa brasileira. Jornais. SNI. Monografia.

Regime militar.
Álvaro Nunes Larangeira | alvarolarangeira@gmail.com Pós-doutor em Jornalismo pela Universidade de Coimbra - Portugal, como bolsista do CNPq, e doutor em Comunicação Social pela Pontifícia Universidade Católica do Rio Grande do Sul, Brasil. É professor adjunto no Mestrado e Doutorado em Comunicação e Linguagens e do curso de Jornalismo da Universidade Tuiuti do Paraná, Brasil.

\section{Introdução}

Em março de 1974, podem ser contabilizados ao regime militar implantado uma década antes 17 atos institucionais e quase uma centena de atos complementares e decretos-lei para ordenar a vida político-social brasileira e depurar a sociedade civil e as estruturas dos poderes Executivo, Legislativo e Judiciário dos cidadãos indesejáveis à classe castrense-civil mandante. Em 10 anos, há 18 mandatos parlamentares cassados, 518 pessoas têm os direitos políticos cassados, com a respectiva perda automática do mandato ou inelegibilidade por 10 anos, e 522 parlamentares são, ao mesmo tempo, cassados e suspensos. Mil cento e vinte e quatro funcionários públicos dos poderes Executivo, Legislativo e Judiciário são contemplados com aposentadoria compulsória, 844 militares são reformados e 1.775 funcionários públicos civil ou militar são demitidos, sem quaisquer ressarcimentos financeiros. No total de 4.841 punições, $78,14 \%$, correspondendo a 3.788 pessoas, são depurados da administração pública, sendo 1.312 militares, 2.081 da administração civil, 146 do Judiciário e 205 da segurança pública; 
e 21,86\% (1.058 indivíduos) correspondem ao sistema político formal, como governantes, senadores, deputados, suplentes, ativistas, militantes e lideranças políticas e sociais. ${ }^{2}$

No começo da década de 1970 se dá 0 recrudescimento por parte do Estado e sua estrutura repressiva na eliminação física dos oponentes, tanto dos grupos optantes pelo enfrentamento armado ao regime militar, como o Partido Comunista do Brasil (PCdoB), quanto das forças políticas com histórico de oposição às ditaduras brasileiras, como o Partido Comunista Brasileiro (PCB). Em outubro de 1973, o governo implementará a terceira incursão militar no Araguaia, no sul do Pará e norte do Tocantins, para, dessa vez, aniquilar os focos guerrilheiros do PCdoB na região. Durante a Operação Marajoara, entre outubro de 1973 e o final do ano seguinte, 56 militantes comunistas serão mortos e terão os corpos ocultados, somando-se ao rol dos 434 mortos e desaparecidos no período da ditadura militar. Em julho de 1974, o presidente da França, Valéry Giscard d’Estaing, solicita ao general Ernesto Geisel a preservação da vida do dirigente comunista do PCB David Capistrano da Costa, por consideração à participação do brasileiro na resistência francesa durante a ocupação nazista. Entretanto, tendo em vista Capistrano da Costa haver sido detido de forma clandestina em março daquele ano, sem notificação oficial da prisão, no decorrer da Operação Radar, destinada a eliminar dirigentes do PCB, o governo brasileiro respondeu desconhecer o paradeiro do comunista, morto e desaparecido no centro clandestino do Centro de Informações do Exército (CIE) em Petrópolis (RJ), a conhecida Casa da Morte.

\section{0 paradigmático $10^{\circ}$ ano do regime militar}

Documento redigido pelo Instituto de Pesquisas e Estudos Sociais (IPES) prognosticava para 1974 a contrarrevolução comunista por meio da imprensa. Entidade lançada em 1962, por representantes do Conselho Nacional das Classes Produtoras (CONCLAP), federações e centros da indústria e comércio do Rio de Janeiro e São Paulo, federações e sindicatos dos bancos paulista e carioca e integrantes da Associação dos Diplomados da Escola Superior de Guerra (ADESG), o IPES compunha uma das tantas organizações latino-americanas idealizadas pelos Estados Unidos no final dos anos 1950 para desestabilizar governos progressistas ou com indícios esquerdistas, supervisionadas pela Central de Inteligência Americana (CIA) e financiadas com recursos do projeto Aliança para o Progresso, multinacionais americanas e grande empresariado local. Na introdução 
do documento da entidade responsável pela fomentação ideológica e suporte financeiromilitar para destituir o presidente João Goulart, 0 redator detalhava o plano comunista: controlar as redações e sucursais das empresas jornalísticas, eleger parlamentares jornalistas e, assim, insuflar a opinião pública e a classe política contra 0 regime revolucionário. ${ }^{3}$

Ainda em 1974, o Serviço Nacional de Informações (SNI), nas instâncias internas, realiza estudo para a reformulação do Conceito Estratégico Nacional, a base para todo o planejamento estratégico nacional, na conceituação do general Golbery do Couto e Silva, ideólogo e implementador do SNI. ${ }^{4} 0$ relato expõe as fendas crescentes no décimo ano do regime militar. Há contestação no partido governista, a Aliança Renovadora Nacional (ARENA), ao processo eleitoral indireto para presidente e governadores. Judiciário e Legislativo tensionam com o Executivo, em especial na concessão dos habeas-corpus, interpretada como desabonador do princípio da autoridade federal. A ONU, no plano externo, e o clero pressionam o governo na questão dos direitos humanos. 0 setor agropecuário destoa do desenvolvimento industrial, forçando a espiral inflacionária. Detecta o SNI abuso do poder econômico na indústria automobilística e na pecuária, infraestruturas rural e urbana deficitárias na distribuição e no escoamento da produção agrícola e industrial, desníveis econômicos e sociais tornam-se visíveis no poder aquisitivo da população - 52,5\% da população ativa recebe menos de um salário mínimo e 22,8\%, entre um e dois - e a preocupante projeção: a elevação do preço do petróleo, imposta pela Organização dos Países Exportadores de Petróleo (OPEP) no ano anterior, estancará o índice do crescimento econômico brasileiro, estandarte do governo até aquele momento. ${ }^{5}$

Esse é o cenário do regime militar em seu décimo ano. Premido pela Igreja Católica, entidades profissionais da classe média e grupos políticos aglutinados no único partido de oposição permitido - 0 Movimento Democrático Brasileiro (MDB) - a adotar a distensão política, atormentado pelo crescimento do custo de vida (pois o índice do preço ao consumidor duplicará entre 1973 e 1974, passando de 13\% para 33,8\%) e à véspera do inexorável declínio do enaltecido Produto Interno Bruto (PIB), o qual diminuirá de 13,6\% para 9,7\%, o governo tem à frente, em 1974, a eleição para a renovação em um terço do Senado e novas composições da Câmara dos Deputados e das assembleias legislativas, a primeira posterior à vitória da ARENA em $92 \%$ dos pleitos municipais em 1972, auge do Milagre Econômico, e com efetiva mobilização das lideranças oposicionistas

Arquivo Nacional, Fundo IPES, documento BR.AN, RI0.QL.0.CDI.37.

COUTO e SILVA, 1981, p. 257.

Arquivo Nacional, Fundo SNI, documento BR AN, BSB N8.0.PSN, EST.40. 
em incorporar a sociedade civil ao debate político por meio de eventos públicos e aproximar-se dos segmentos populares aproveitando o espaço da propaganda eleitoral na rádio e TV para desconstruir o discurso governista apologético da segurança nacional e da irreversibilidade do desenvolvimentismo econômico e social.

\section{A monografia da imprensa brasileira}

0 SNI foi implantado em 13 de junho de 1964, no governo Castello Branco, sob a coordenação de Couto e Silva. Redator do Memorial dos Coronéis, manifesto lançado em janeiro de 1954 e subscrito por 42 coronéis e 39 tenentes-coronéis da ativa, responsabilizando, nas entrelinhas, o ministro do Trabalho do governo Vargas, João Goulart, por influências esquerdistas nas Forças Armadas, Golbery foi exonerado em 1955 das funções de adjunto do Departamento de Estudos da Escola Superior de Guerra e transferido para $0 \mathrm{QG}$ da ID/4 em Belo Horizonte. No ano seguinte, promovido a coronel, integrou a Subseção de Doutrina da Seção de Operações do EstadoMaior das Forças Armadas, tornando-se chefe do setor em setembro de 1960. Em fevereiro de 1961, início do mandato de Jânio Quadros, foi nomeado chefe de gabinete da Secretariageral do Conselho de Segurança Nacional, de onde requisitou a transferência para a reserva quando os ministros militares aceitaram a posse do vice-presidente João Goulart, substituto constitucional do renunciante Jânio Quadros, sob a condição da alteração do sistema político para o parlamentarismo.

Golbery do Couto e Silva passa então a dirigir, desde a fundação, o Grupo de Levantamento da Conjuntura do IPES, responsável no plano teórico das avaliações conjunturais do país e todos os acontecimentos políticos e, no plano prático, a articulação da entidade com militares e setores de informação das áreas operacionais em todas as regiões militares, com vistas a desacreditar 0 governo Goulart e apeá-lo do poder. 0 grupo mantinha uma rede nas capitais e abastecia empresários, políticos, militares, religiosos, estudantes e militantes das associações populares e operárias antagonistas ao movimento operário e sindical de esquerda com centenas de artigos e publicações mensais, remetidas às organizações e simpatizantes e divulgadas parte na imprensa, a pedido ou por afinidade dos meios de comunicação. 0 material da clipagem diária dos jornais do Rio de Janeiro, São Paulo, Belo Horizonte, Porto Alegre, Recife, Curitiba, Fortaleza e Salvador, das revistas semanais 0 Cruzeiro, Manchete, Visão, Fatos \& Fotos e publicações de menor tiragem, as anotações dos milhares de telefones grampeados (3 mil apenas no Rio de Janeiro) e os arquivos e dossiês de 400 mil pessoas e dos grupos considerados associados ao comunism $0^{6}$, operacionalizados pelas entidades filiadas ao IPES, formaram o acervo primário 
do SNI, acrescido da documentação do Serviço

Federal de Informações e Contra-Informações

(SFICI) da Secretaria-geral do Conselho de

Segurança Nacional.

Considerando a imprensa o espaço da construção semântica da opinião pública e das representações da sociedade e demandas do campo político, Golbery, então chefe do Gabinete Civil do governo Geisel, aciona 0 SNI para solicitar às 12 agências regionais 0 mapeamento da imprensa nas respectivas jurisdições (a agência Belém responderia pelo Pará; Belo Horizonte, Minas Gerais; Brasília, Distrito Federal e Goiás; Campo Grande, Mato Grosso; Curitiba, Paraná e Santa Catarina; Fortaleza comportaria Ceará, Maranhão e Piauí; Manaus, no caso Acre, Amazonas e os territórios do Amapá, Rondônia e Roraima; Porto Alegre, o Rio Grande do Sul; Recife, a parte nordestina referente a Alagoas, Paraíba,
Pernambuco e Rio Grande do Norte; Rio de Janeiro abarcava Espírito Santo, Guanabara e o Estado do Rio de Janeiro; Salvador, Bahia; e a agência da capital paulista, São Paulo), listando os proprietários e a situação legal das empresas amparada em documentação dos cartórios ou juntas comerciais, dados da circulação e zona de influência das publicações, particularidades relevantes, as linhas de atuação do ponto de vista político e o posicionamento editorial de cada um quanto aos governos federal, estadual e local (figuras 1 e 2).

0 levantamento das sucursais do SNI culminou em dois arquivos, com um total de 169 páginas, encontrados pelo pesquisador no Arquivo Nacional do Rio de Janeiro durante investigação sobre a responsabilidade da mídia no golpe militar de 1964. 0 conteúdo explicita as contendas internas dentro do partido governista e registra

Figura 1 e 2: Modelos do envio das informações solicitadas.

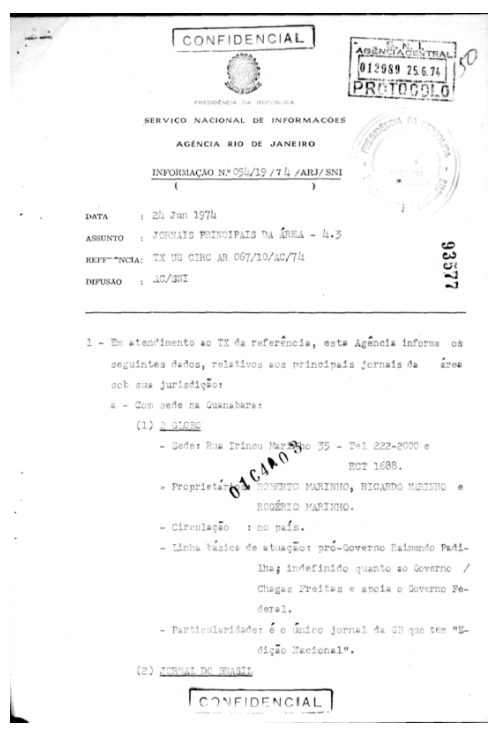

\begin{tabular}{|c|c|c|c|c|c|}
\hline \multirow[b]{2}{*}{ NOME } & \multicolumn{5}{|c|}{$\begin{array}{l}\text { Confidencial } \\
\text { QUADRO DERONSTRATIVO DAS EMPRESAS JORNaLISTICAS DA AREA DE JURISDTÇAO DA AMA/SNI }\end{array}$} \\
\hline & $\begin{array}{lll} & B & D \\
\end{array}$ & CIDADE & PSTADO & \begin{tabular}{|l|} 
PROPRIETARTO \\
\end{tabular} & crince \\
\hline $\begin{array}{l}\text { "A NOTICIA" } \\
\text { "A CRITICA" } \\
\text { "JORNAL DO COMER- } \\
\text { CIO" } \\
\text { "O JORNAL" } \\
\text { "DIKRIO DA TARDE" }\end{array}$ & $\begin{array}{l}\text { Pẹa. Tenreiro Aranha, } 33 \\
\text { Rua Lôbo d'Almađa, } 278 \\
\text { Av. Edùarco Ribeiro, } 566 \\
\text { Av. Eduarso Ribeiro, } 556\end{array}$ & 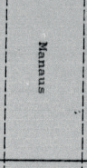 & 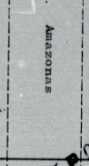 & $\begin{array}{l}\text { MANOEL JOSE DE ANDRADE NETO } \\
\text { E ELIZABETH FINA DE ANDRADE } \\
\text { IMBERTO CALDERARO FTLHO } \\
\text { DIARTOS ASSOCTADOS } \\
\text { MARTA DE LOURDES ARCHER } \\
0 \text { PINTO }\end{array}$ & $\begin{array}{l}\text { Estado do } \\
\text { Estado do } \\
\text { Colomb1a } \\
\text { Estado do } \\
\text { Estado do }\end{array}$ \\
\hline "O RIO BRANCO" & Rua Cel. Joăo Donato & $\begin{array}{c}\mathrm{Rio} \\
\text { Branco }\end{array}$ & 10 & DTÁRIOS ASSOCTADOS & Estado do \\
\hline "O BOA vista" & Boa Vista/RR & $\begin{array}{c}\text { Boa } \\
v_{1} \text { sta }\end{array}$ & Roraima & GOVERNO DO TERRITORIO & $\begin{array}{l}\text { Territór } 1 \\
\text { Roraima }\end{array}$ \\
\hline "ALTO MADE TRA" & Pq̧a. Jonathas Pedrosa, 505 & $\begin{array}{l}\text { Porto } \\
\text { Velho }\end{array}$ & Rondônia & DIRRIOS ASSOCIADOS & $\begin{array}{l}\text { Territóri } \\
\text { Rondonia }\end{array}$ \\
\hline "O СОМВАTE" & Av. Duque de Caxias, 2196 & $\begin{array}{l}\text { Porto } \\
\text { Veltho } \\
\end{array}$ & |Rondôn1a & TRATY MENDES DA SILYA & $\begin{array}{l}\text { Torritóri } \\
\text { Rondônia } \\
\end{array}$ \\
\hline "O GUAPORE" & Av, Press. Dutra, 195 & \begin{tabular}{|l|}
$\begin{array}{l}\text { Porto } \\
\text { Velho } \\
\end{array}$ \\
\end{tabular} & Rondônia & \begin{tabular}{l|} 
EMANUEL PONTES PTNTO \\
MAICY GUARANY, WANDERLEY \\
\end{tabular} & $\begin{array}{l}\text { Territíri } \\
\text { Rondonia } \\
\end{array}$ \\
\hline "O IMPARCIAL" & Av. Leopoldo de Matos, 388 & \begin{tabular}{|c|} 
Guajará \\
Mirim
\end{tabular} & Rondônia & EMILIO RODRIGUES SANTIAGO & $\begin{array}{l}\text { Territíni } \\
\text { Rondonia } \\
\text { rim (extr }\end{array}$ \\
\hline "A PALAVRa" & Rua Tenente Brasili, s/n & \begin{tabular}{|l|l|l} 
vile de \\
Roncônial \\
\end{tabular} & Rondonia & 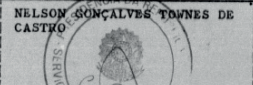 & $\begin{array}{l}\text { Territóri } \\
\text { Rondonia } \\
\text { Ac. Humai } \\
\text { ramorim }\end{array}$ \\
\hline
\end{tabular}


os grupos locais governistas no extrato federal e dissonantes nas disputas políticas estaduais e regionais, motivo pelo qual o presidente Ernesto Geisel evocaria no pronunciamento, no final de ano de 1974, para explicar a expressiva derrota da ARENA nas eleições legislativas, com o MDB elegendo 16 dos 22 senadores, duplicando a bancada na Câmara dos Deputados e obtendo a maioria nas assembleias legislativas em São Paulo, Guanabara, Rio de Janeiro, Rio Grande do Sul, Amazonas e Acre. ${ }^{7} 0$ documento também expõe as dessemelhanças interpretativas dos quesitos requisitados e nos ajuizamentos em determinadas sucursais, demonstrando dissensões valorativas nas conceituações referentes à temática da segurança nacional, mesmo com a tentativa regimental de normatizar a formação funcional por intermédio da Escola Nacional de Informações (EsNI), criada em 1971.

No entanto, a contribuição medular da investigação protagonizada pela espionagem estatal, ao tomar a imprensa como objeto empírico, é relativa aos estudos da mídia brasileira e, por extensão, à epistemologia jornalístico-comunicacional. 0 inventário dos principais jornais da época reporta às políticas de comunicação no Brasil e 0 ancestral compadrio do poder público com as lideranças coronelistas, o exponencial monopólio da propriedade na esfera midiática pela classe política e 0 tácito e implícito acobertamento do Estado no desrespeito aos princípios constitucionais do veto a parlamentares na direção e administração de empresas beneficiadas por concessões públicas (emissoras de rádio e televisão, por exemplo), a defasagem da perspectiva funcionalista de atribuir à imprensa 0 inerente princípio panóptico da vigilância virtuosa do poder em relação à preponderância contemporânea do intrínseco caráter intervencionista da mídia, seu poder de achaque, negociação e domínio de outros campos e 0 eminente papel de instabilizadora e/ou legitimadora dos sistemas de governo e regimes políticos. Se na monografia da imprensa parisiense Balzac descrevia os protótipos humanos constitutivos do universo redacional, no arrazoado do SNI temos a materialização do princípio monográfico da representação metódica da personalidade e lugar de fala das empresas jornalísticas, pela ótica exterior à tribo jornalística, em interação com fatores, elementos e agentes epocais, incitando a exposição do comportamento midiático a exegeses universalizantes ou procedimentos circunstanciáveis.

No consciencioso trabalho executado pelas sucursais do SNI, são listados 22 jornais no Centro-Oeste; 32 no Nordeste; 15 no Norte; 7 na cidade do Rio de Janeiro; 2 no Espírito Santo; 4 em Minas Gerais; 2 no Estado do Rio de Janeiro; 4 paranaenses; 2 em Santa Catarina, 77 no Rio Grande do Sul e 113 em São Paulo. Por que a discrepante diferença dos dados dos dois últimos 
Estados se comparados aos demais? Por causa de interpretação e sistemática peculiares nos dois casos. A agência gaúcha enviou à agência central a relação dos jornais em Porto Alegre, Caxias do Sul, Passo Fundo, Pelotas e Santana do Livramento - a capital, o segundo centro urbano do Estado e as cidades limítrofes ao norte, sul e fronteira-oeste -, com os respectivos proprietários e área de influência, e mais uma lista com as publicações de 52 outros municípios, sem as demais informações solicitadas. Por parte da agência paulista, foram remetidas à capital federal 24 folhas com a transcrição de 113 jornais, 6 revistas, 83 publicações segmentadas, 104 emissoras de rádio, 5 canais de televisão e 11 agências de notícias extraídos da seção relativa ao Estado de São Paulo no Anuário Brasileiro de Propaganda, edição 1973-1974, com a promessa do envio futuro da análise de conteúdo de cada um dos citados. As duas agências foram posteriormente cobradas da documentação faltante, porém os complementos, se foram expedidos, não foram localizados pelo pesquisador no Arquivo Nacional, podendo encontrar-se no meio das 220 mil microfichas do acervo dos órgãos de segurança e informação encaminhado ao Arquivo Nacional em $2005^{8}$ e ainda em processo de catalogação. Por essa razão, os materiais do Rio Grande do Sul e de São Paulo foram desconsiderados na contagem e lista dos impressos reportados pelo SNI.

\section{Análise dos jornais com base nos enquadramentos do SNI}

Foram efetivamente analisados 90 jornais, especificados a seguir por região e com as apreciações literais constantes nas microfichas:

\begin{tabular}{|c|c|c|}
\hline \multicolumn{3}{|c|}{ CENTRO-OESTE } \\
\hline Publicação & Linha editorial federal & Linha editorial estadual \\
\hline Correio Braziliense (DF) & \multicolumn{2}{|c|}{ De inspiração democrática, identificado com o atual regime brasileiro. } \\
\hline Diário de Brasília (DF) & \multicolumn{2}{|c|}{$\begin{array}{l}\text { De inspiração democrática, identificado com o governo. Linguagem comedida } \\
\text { nas críticas a atos do governo ou de autoridades federais e do Distrito Federal. }\end{array}$} \\
\hline Jornal de Brasília (DF) & \multicolumn{2}{|c|}{$\begin{array}{l}\text { De inspiração democrática, embora veemente nas críticas ao governo, } \\
\text { principalmente a fatos ocorridos no gov. do Pres. Médici. }\end{array}$} \\
\hline Cinco de Março (G0) & \multicolumn{2}{|c|}{$\begin{array}{l}\text { Por orientação do proprietário, não se observa campanha sistemática contra } \\
\text { o governo federal ou estadual. }\end{array}$} \\
\hline Folha de Goiaz (G0) & \multicolumn{2}{|c|}{$\begin{array}{l}\text { Oportunista em termos políticos. Linha mais equilibrada em matéria ideológica, } \\
\text { refletindo a orientação do Condomínio Associado. }\end{array}$} \\
\hline 0 Popular (G0) & Não tem trazido maiores problemas à Censura Federal. & $\begin{array}{l}\text { Oportunista. No momento, } \\
\text { apoia o governo estadual. }\end{array}$ \\
\hline Correio da Imprensa (MT) & \multirow{3}{*}{\multicolumn{2}{|c|}{$\begin{array}{l}\text { Face governo federal: todos manifestam-se favoravelmente; } \\
\text { face governo estadual: apenas "Equipe" mantém orientação política contrária. }\end{array}$}} \\
\hline Correio do Estado (MT) & & \\
\hline Correio do Povo (MT) & & \\
\hline
\end{tabular}




\begin{tabular}{|c|c|c|}
\hline \multicolumn{3}{|c|}{ CENTRO-OESTE } \\
\hline Publicação & Linha editorial federal & Linha editorial estadual \\
\hline Correio do Sudoeste (MT) & \multirow{13}{*}{\multicolumn{2}{|c|}{$\begin{array}{l}\text { Face governo federal: todos manifestam-se favoravelmente; } \\
\text { face governo estadual: apenas “Equipe" mantém orientação política contrária. }\end{array}$}} \\
\hline Diário da Serra (MT) & & \\
\hline Diário de Corumbá (MT) & & \\
\hline Diário de Cuiabá (MT) & & \\
\hline Equipe (MT) & & \\
\hline Folha da Tarde (MT) & & \\
\hline Jornal da Manhã (MT) & & \\
\hline Jornal do Povo (MT) & & \\
\hline Luta Matogrossense (MT) & & \\
\hline 0 Estado do Mato Grosso (MT) & & \\
\hline 0 Momento (MT) & & \\
\hline 0 Progresso (MT) & & \\
\hline Tribuna do Leste (MT) & & \\
\hline
\end{tabular}

\begin{tabular}{|c|c|c|}
\hline \multicolumn{3}{|c|}{ NORDESTE } \\
\hline Publicação & Linha editorial federal & Linha editorial estadual \\
\hline Gazeta de Alagoas (AL) & \multirow{2}{*}{\multicolumn{2}{|c|}{ Democrática. Apoio aos governos federal e estadual. }} \\
\hline Jornal de Alagoas (AL) & & \\
\hline A Tarde (BA) & \multicolumn{2}{|c|}{$\begin{array}{l}\text { Apoia de modo discreto os governos estadual, municipal e federal. } \\
\text { Quando tem oportunidade faz crítica ao regime atual. }\end{array}$} \\
\hline Diário de Notícias (BA) & \multicolumn{2}{|c|}{$\begin{array}{l}\text { Apoia sem restrições aos governos federal, estadual e municipal } \\
\text { e faz propaganda ostensiva dos dois últimos. }\end{array}$} \\
\hline Jornal da Bahia (BA) & $\begin{array}{l}\text { Apoio crescente ao governo federal, sobretudo na } \\
\text { política econômica e populacional, com restrições } \\
\text { seguidas ao BNH, INPS e SUNAB. }\end{array}$ & $\begin{array}{l}\text { Após incidente com ACM, passou a fazer } \\
\text { oposição sistemática ao governador e ao } \\
\text { prefeito de Salvador. }\end{array}$ \\
\hline Tribuna da Bahia (BA) & Jornal de tendência liberal e "avançada". & $\begin{array}{l}\text { Embora considerado um órgão que apoia os } \\
\text { governos estadual e municipal, por não criticar } \\
\text { diretamente seus titulares, faz críticas severas } \\
\text { aos secretários e órgãos públicos. }\end{array}$ \\
\hline Correio do Ceará (CE) & \multirow{5}{*}{ Não especificado } & $\begin{array}{l}\text { Sensacionalista. Costuma inserir notícias } \\
\text { inverídicas e boatos. Possui uma colunista que, } \\
\text { sistematicamente, critica o governo estadual. }\end{array}$ \\
\hline 0 Estado (CE) & & $\begin{array}{l}\text { Sensacionalista. Explora a divulgação de } \\
\text { crimes e escândalos. Apela constantemente } \\
\text { para o tema sexo. }\end{array}$ \\
\hline 0 Povo (CE) & & \multirow{2}{*}{ De modo geral favorável ao governo estadual. } \\
\hline Tribuna do Ceará (CE) & & \\
\hline Unitário (CE) & & Segue a mesma linha do Correio do Ceará. \\
\hline
\end{tabular}




\begin{tabular}{|c|c|c|}
\hline \multicolumn{3}{|c|}{ NORDESTE } \\
\hline Publicação & Linha editorial federal & Linha editorial estadual \\
\hline Jornal Pequeno (MA) & \multirow{3}{*}{ Não especificado } & $\begin{array}{l}\text { Sensacionalista. Exploração de crimes e } \\
\text { escândalos. }\end{array}$ \\
\hline $\begin{array}{l}0 \text { Estado do Maranhão } \\
\text { (MA) }\end{array}$ & & $\begin{array}{l}\text { Independente. Segue orientação do senador } \\
\text { José Sarney. }\end{array}$ \\
\hline 0 Imparcial (MA) & & $\begin{array}{l}\text { Independente. Segue, de modo geral, a linha de } \\
\text { conduta dos demais órgãos associados do país. }\end{array}$ \\
\hline Correio da Paraíba (PB) & \multirow{4}{*}{\multicolumn{2}{|c|}{ Democrática. Apoio aos governos federal e estadual. }} \\
\hline 0 Norte (PB) & & \\
\hline $\begin{array}{l}\text { Diário de Pernambuco } \\
\text { (PE) }\end{array}$ & & \\
\hline $\begin{array}{l}\text { Jornal do Commercio } \\
\text { (PE) }\end{array}$ & & \\
\hline A Hora (PI) & \multirow{8}{*}{ Não especificado } & Oposição ao governo estadual. \\
\hline Folha do Litoral (PI) & & \multirow[b]{2}{*}{ Favorável ao governo estadual. } \\
\hline Jornal do Piauí (PI) & & \\
\hline 0 Dia (PI) & & Linha independente. \\
\hline 0 Estado (PI) & & Favorável ao governo estadual. \\
\hline 0 Estado do Piauí (PI) & & Oposição ao governo estadual. \\
\hline 0 Liberal (PI) & & Favorável ao governo estadual. \\
\hline 0 Norte do Piauí (PI) & & Oposição ao governo estadual. \\
\hline Diário de Natal (RN) & \multicolumn{2}{|c|}{ Democrática. Apoio aos governos federal, estadual e municipal. } \\
\hline Tribuna do Norte (RN) & \multicolumn{2}{|l|}{ Oposicionista. Apoio total ao MDB. } \\
\hline Diário de Aracaju (SE) & \multicolumn{2}{|c|}{$\begin{array}{l}\text { Segue a linha geral dos Diários Associados, inclusive transcrevendo os editoriais do Sul da mesma } \\
\text { cadeia. Apoia os governos federal, estadual e municipal. }\end{array}$} \\
\hline Gazeta de Sergipe (SE) & \multicolumn{2}{|c|}{$\begin{array}{l}\text { Adota posição de relativa independência, com críticas construtivas a medidas dos governos estadual } \\
\text { e municipal. Tem apoiado as medidas do governo federal e ressaltado os seus êxitos. }\end{array}$} \\
\hline Jornal da Cidade (SE) & \multirow{2}{*}{\multicolumn{2}{|c|}{ Apoia os governos federal, estadual e municipal. }} \\
\hline Tribuna de Aracaju (SE) & & \\
\hline
\end{tabular}

\begin{tabular}{|l|l|}
\multicolumn{1}{|c|}{ Publicação } & \multicolumn{1}{c|}{ Linha editorial federal } \\
\hline 0 Rio Branco (AC) & Linha de atuação neutra. Raramente comenta fatos de natureza política. \\
\hline A Crítica (AM) & Linha de atuação heterogênea. \\
\hline A Notícia (AM) & Nada consta. \\
\hline Diário da Tarde (AM) & Adota o mesmo critério do matutino 0 Jornal. \\
\hline Jornal do Comércio (AM) & Linha de atuação neutra. Raramente comenta fatos de natureza política. \\
\hline 0 Jornal (AM) & $\begin{array}{l}\text { Sem linha de atuação definida. Define de acordo com as conveniências pessoais } \\
\text { e econômicas da proprietária. }\end{array}$ \\
\hline
\end{tabular}




\begin{tabular}{|c|c|c|}
\hline \multicolumn{3}{|c|}{ NORTE } \\
\hline Publicação & Linha editorial federal & Linha editorial estadual \\
\hline A Província do Pará (PA) & \multirow{3}{*}{$\begin{array}{l}\text { Apoio, de modo geral, às iniciativas } \\
\text { do governo federal. }\end{array}$} & Defende 0 atual governo. \\
\hline Folha do Norte (PA) & & Neutra. \\
\hline 0 Liberal (PA) & & Neutra. \\
\hline Alto Madeira (R0) & \multicolumn{2}{|c|}{ Linha de atuação neutra. Raramente comenta fatos de natureza política. } \\
\hline A Palavra (R0) & \multicolumn{2}{|l|}{ Nada registra que desabone sua linha de conduta. } \\
\hline 0 Combate (R0) & $\begin{array}{l}\text { Adota uma linguagem incompatível com órgão de } \\
\text { imprensa. Procura sempre depreciar autoridades. }\end{array}$ & $\begin{array}{l}\text { É um jornal de oposição que realiza } \\
\text { sistemáticas e violentas críticas às autoridades } \\
\text { do Território. }\end{array}$ \\
\hline 0 Guaporé (R0) & \multicolumn{2}{|c|}{$\begin{array}{l}\text { Sua linha de ação é imparcial. Tem como critério informar a opinião pública objetivamente, sem } \\
\text { distorcer a realidade dos acontecimentos. }\end{array}$} \\
\hline 0 Imparcial (R0) & \multicolumn{2}{|l|}{ Nada registra que desabone sua linha de conduta. } \\
\hline 0 Boa Vista (RR) & \multicolumn{2}{|l|}{ Órgão do governo do Território de Roraima. } \\
\hline
\end{tabular}

\begin{tabular}{|c|c|c|}
\hline \multicolumn{3}{|c|}{ SUDESTE } \\
\hline Publicação & Linha editorial federal & Linha editorial estadual \\
\hline A Gazeta (ES) & \multirow{2}{*}{ Apoia a Arena e o governo federal. } & Atualmente, apoia o governo do Estado. \\
\hline A Tribuna (ES) & & Não apoia o governo estadual. \\
\hline A Notícia (GB) & \multicolumn{2}{|l|}{ Idêntica ao 0 Dia. } \\
\hline Diário de Notícias (GB) & Adota posição de equilíbrio em relação ao governo. & É contra o governo Chagas Freitas. \\
\hline Jornal do Brasil (GB) & Linha de editoriais favorável ao governo federal. & Pró-governo Chagas Freitas. \\
\hline $0 \mathrm{Dia}(\mathrm{GB})$ & Não radical contra o governo federal. & Apoia o governo Chagas Freitas. \\
\hline 0 Globo (GB) & Apoia o governo federal. & Indiferente ao governo Chagas Freitas. \\
\hline Tribuna da Imprensa (GB) & $\begin{array}{l}\text { É normalmente contra o governo federal, só sendo } \\
\text { favorável quando há coincidência de objetivos. }\end{array}$ & \multirow{2}{*}{ Opõe-se ao governo Chagas Freitas. } \\
\hline Última Hora (GB) & Apoia o governo federal. & \\
\hline Diário da Tarde (MG) & \multicolumn{2}{|l|}{ Segue a mesma linha do Estado de Minas. } \\
\hline Diário de Minas (MG) & \multicolumn{2}{|l|}{ Linha moderada de atuação. } \\
\hline Estado de Minas (MG) & \multicolumn{2}{|l|}{ Mantém linha de conduta moderada e conservadora. } \\
\hline Jornal de Minas (MG) & \multicolumn{2}{|c|}{$\begin{array}{l}\text { Tem procurado criar imagem de jornal independente junto à opinião pública. Recorre ao } \\
\text { sensacionalismo e não possui linha ideológica definida. }\end{array}$} \\
\hline A Tribuna (RJ) & $\begin{array}{l}\text { Não apresenta uma posição definida em relação ao } \\
\text { governo federal. Apoia o MDB. }\end{array}$ & $\begin{array}{l}\text { Opõe-se ao governo Padilha. Combate } \\
\text { sistematicamente a corrupção na } \\
\text { administração pública. }\end{array}$ \\
\hline 0 Fluminense (RJ) & Combate sistemático ao aumento do custo de vida. & $\begin{array}{l}\text { Embora apoie a Arena, não se engaja no } \\
\text { esquema do governo Padilha. }\end{array}$ \\
\hline
\end{tabular}




\begin{tabular}{|l|l|l|}
\multicolumn{1}{|c|}{ Publicação } & Linha editorial federal & Linha editorial estadual \\
\hline Diário do Paraná (PR) & \\
\hline Folha de Londrina (PR) & \\
\hline Gazeta do Povo (PR) & Democrática liberal. \\
\hline 0 Estado do Paraná (PR) & \\
\hline 0 Estado (SC) & \\
\hline $\begin{array}{l}\text { Jornal de Santa Catarina } \\
\text { (SC) }\end{array}$ & \\
\hline
\end{tabular}

0 ordenamento das informações nos quadros prioriza a postura política e editorial dos meios impressos em relação aos governos federal e estadual, passados 10 anos do regime militar. Em todo o material, somente dois jornais são alçados à categoria de oposição efetiva: a

Tribuna do Norte, no Rio Grande do Norte, e a Tribuna da Imprensa, na Guanabara, e por motivos antagônicos e similares. 0 diário potiguar pertence à família de Aluízio Alves, ex-deputado federal pela União Democrática Nacional (UDN), Partido Social Democrático (PSD) e ARENA e governador entre 1961 e 1966. Cassado com suspensão por 10 anos dos direitos políticos por decreto respaldado pelo Ato Institucional $n^{0} 5$ (AI5) em fevereiro de 1969, Aluízio Alves ingressa no MDB em 1970 e arregimenta correligionários para a oposição. A Tribuna da Imprensa, por sua vez, envereda para a crítica ao governo militar quando Castello Branco suspende, em 1965, as eleições presidenciais diretas, inviabilizando as intenções de Carlos Lacerda, ex-proprietário do jornal e por quem a Tribuna da Imprensa fazia ostensiva campanha ao Palácio do Planalto. A publicação lacerdista perfilar-se-á à linha dura da área militar, e o jornalista Hélio Fernandes, participante do grupo dos extremistas de direita do IPES $^{9}$ e dono do jornal desde 1962, perderá os direitos políticos em novembro de 1966, à véspera da eleição para a qual concorreria como candidato federal pelo MDB da Guanabara, será deportado para Fernando de Noronha pelo presidente Costa e Silva em 1967, por dois artigos considerados desrespeitosos à memória de Castello Branco, e motivará no informe da agência carioca o comentário no item Particularidades sobre a Tribuna da Imprensa: "Um de seus acionistas, Hélio Fernandes, mantém amplas relações com os elementos radicais de direita". ${ }^{10}$

Tangenciam a zona de preocupação o Jornal de Brasília, no Distrito Federal, o semanário Cinco de Maio, em Goiânia, a Tribuna da Bahia, em

\section{DREIFUSS, p. 371.}

10 Documento AC-ACE-93577/74-001, p. 59, Fundo SNI, Arquivo Nacional. 
Salvador, e o associado Correio do Ceará, em Fortaleza. 0 primeiro faz parte das Organizações Jaime Câmara, tem difusão nacional nos meios políticos, é incisivo nos julgamentos do governo federal e "sensacionalista na divulgação de denúncias contra irregularidades em órgãos públicos". ${ }^{11}$ Embora Wagner Tavares de Goes e Jaime Câmara Júnior constassem como proprietários, o verdadeiro dono da publicação, fato destacado pela sucursal, era Jaime Câmara, delegado em Goiás no governo João Goulart da Superintendência de Política Agrária (SUPRA), abominada pelos golpistas de 1964, e deputado federal arenista destituído do mandato em 1969 porque, no episódio determinante para a instituição do AI-5, votou contra a cassação do jornalista e deputado federal emedebista Márcio Moreira Alves, exigência do governo militar ao Congresso Nacional. Quanto ao Cinco de Maio, a desconfiança provinha de ser Haroldo de Brito Guimarães diretor de redação, punido pelo primeiro ato institucional do regime, sob a pecha de comunista. Por isso, a sucursal anexa 0 boletim de expedição do jornal Cinco de Maio com a relação e o endereço dos 191 distribuidores da publicação no território nacional.

A Tribuna da Bahia recebe comentário peculiar da agência local: "Apesar de sua recente mudança de orientação, adotando uma linha mais conservadora e equilibrada, é o jornal que mais causa preocupação a ASV/SNI, que vem acompanhando atentamente a sua conduta". ${ }^{12} 0$ jornal foi fundado em 1969, tendo como redatorchefe J. Quintino de Carvalho, citado como um dos quatro jornalistas responsáveis por 0 Momento no índex dos jornais comunistas listados no Inquérito Policial Militar $n^{0} 709$, sobre 0 comunismo no Brasil, finalizado em $1966 .{ }^{13}$ Quintino de Carvalho, ao falecer, foi substituído por Milton Cayres de Brito, componente do Comitê Central do PCB, eleito na III Conferência Nacional do partido, em 1946. A alteração administrativa, com 0 empresário Joaci Fonseca de Góes assumindo o jornal, pouco arrefece a suspeita referente à linha editorial, caracterizada por "destaque exagerado para as notícias relativas aos programas governamentais e minimização dos êxitos, simpatia pelo bloco socialista e críticas severas aos Estados Unidos e ao bloco ocidental, fotos e manchetes de dupla interpretação e seleção capciosa de notícias"14, derivada da "notória influência de elementos de esquerda na redação". ${ }^{15}$

Apesar de integrar o conglomerado midiático situacionista dos Diários Associados, o Correio do Ceará desperta cuidado da sucursal

11 Documento AC-ACE-93577/74-001, p. 97, Fundo SNI, Arquivo Nacional.

12 Documento AC-ACE-93577/74-002, p. 39, Fundo SNI, Arquivo Nacional.

13 CARVALHO (org.), 1967, p. 97.

14 Documento AC-ACE-93577/74-002, p. 38, Fundo SNI, Arquivo Nacional. 
por razão idêntica ao Cinco de Maio: tem em seus quadros jornalistas incluídos em averiguações e inquéritos policiais militares. "Tem como editor-chefe Francisco Teobaldo Mourão Landim, possuidor de registros que o caracterizam como esquerdista. Francisco Teobaldo Mourão Landim, que exerce a função de diretor da central informativa dos 'Diários e Rádios Associados' no Ceará, foi objeto dos doc. Info. 938 e 979/19/AFZ/73 e 094/19/AFZ/74", especifica 0 documento na parte destinada a "observações", para, na coluna "linha básica de atuação", ser conceituado como "sensacionalista". Esse termo, também aplicado ao Jornal de Brasília, tem significado diferente nos dois casos do sentido pejorativo usualmente utilizado no meio jornalístico e também usado pelo SNI. Há nele a dimensão político-ideológica atribuída pela ideologia de segurança nacional do regime militar, assim detalhada no terceiro volume do Inquérito Policial Militar $\mathrm{n}^{0} 709-0$ Comunismo no Brasil:

Técnica de propaganda sutil - Fotografias ou noticiários depreciativos do regime capitalista, notícias alarmantes sôbre crises ou ameaças, aspectos de miséria das populações, críticas sobre as violências policiais, demonstração de corrupção e degradação moral no regime vigente, são assuntos que hábilmente manipulados, deixam de constituir simples noticiário ou jornalismo construtivo, para se tornarem veículos de propaganda sutil dos comunistas para a desmoralização do regime e 0 descrédito da ordem vigente no conceito popular. ${ }^{16}$

\section{Considerações finais}

As considerações das agências do Serviço Nacional de Informações sobre os principais jornais em todo o país ensejam uma multiplicidade analítica sob perspectivas diversas. Do entendimento dos termos "democrático", "democrático-liberal", "neutro" e "linha moderada de atuação", das razões para abordagens distintas dentro do próprio órgão centralizador do sistema de informação e contrainformação do regime militar às implicações culturais, históricas, políticas e sociológicas acomodadas nesse expressivo retrato midiático, à mercê de exames pluridisciplinares.

No tocante aos campos do jornalismo e da comunicação, searas do pesquisador, a monografia da imprensa brasileira costurada a partir da documentação do SNI contribui em amplificar o horizonte da historiografia jornalística e da História da Comunicação, comumente direcionadas para o Rio de Janeiro e São Paulo, ficando os trabalhos regionais e locais restritos a rodear o campo magnético do objeto de estudo convencional. 0 levantamento aqui esquadrinhado comporta abrangência singular nos estudos da memória jornalística no período 1964-1985.

Por último, optou-se pela partícula do paralelismo mídia e regime militar para reiterar a identificação orgânica das empresas de comunicação com o ideário dos governos militares e, assim, 
deslegitimar a recorrente falácia do mainstream midiático de alinhamentos correspondentes à época do respaldo da sociedade ao sistema implementado em 1964, sempre reavivada em datas efemérides, como ocorreu no ano passado com os 50 anos do golpe e pode ser repetido agora com os 30 anos do final da ditadura militar.

\section{Referências bibliográficas e documentais}

\section{Bibliográficas:}

A COMUNIDADE ganhou. Veja. Brasília, ed. 616, 25 jun. 1980.

ALVES, Maria Helena Moreira. Estado e Oposição no

Brasil (1964-1984). $5^{\mathrm{a}}$ ed. Petrópolis: Vozes, 1984.

BAFFA, Ayrton. Nos porões do SNI: 0 retrato do monstro de cabeça oca. Rio de Janeiro: Objetiva, 1989.

BALZAC, Honoré de. 0s jornalistas. Rio de Janeiro: Ediouro, 2004.

BRASIL. COMISSÃO NACIONAL DA VERDADE.

Relatório. 3 v. Disponível em: http://www.cnv.gov.br/ images/pdf/relatorio/volume_1_digital.pdf. Acesso em: 15 fev. 2015

CADIOU, François et al. Como se faz a História: historiografia, método e pesquisa. Petrópolis: Vozes, 2007.

CARVALHO, Ferdinando (org.). 0 Comunismo no Brasil: Inquérito policial militar $n^{0} 709$. Volume III: A agitação e a propaganda. Rio de Janeiro: Biblioteca do Exército, 1967.

COMISSÃO DE FAMILIARES MORTOS E DESAPARECIDOS POLÍTICOS; INSTITUTO DE ESTUDO DA VIOLÊNCIA DO ESTADO; GRUPO TORTURA NUNCA MAIS. Dossiê dos mortos e desaparecidos políticos a partir de 1964. São Paulo: Imprensa Oficial do Estado, 1995.

COUTO e SILVA, Golbery do. Conjuntura política nacional \& geopolítica do Brasil. $2^{\mathrm{a}}$ ed. Rio de Janeiro: José Olympio Editora, 1981.

DREIFUSS, René Armand. 1964: a conquista do Estado: ação política, poder e golpe de classe. $2^{\mathrm{a}} \mathrm{ed}$. Petrópolis: Vozes, 1981.

FIC0, Carlos. A ditadura documentada. ACERV0 Revista do Arquivo Nacional, v. 21, n. 2, p. 67-78, jul./ $\operatorname{dez} / 2008$.

Como eles agiam: os subterrâneos da ditadura militar: espionagem e polícia política. Rio de Janeiro: Record, 2001.

FIGUEIRED0, Marcus Faria. A política de coação no Brasil pós-64. In: FIGUEIRED0, Marcus; KLEIN, Lúcia. Legitimidade e Coação no Brasil pós-64. Rio de Janeiro: Forense-Universitária, 1978.

FRANC0, Pablo E.; ISHAQ, Vivien. Os acervos dos órgãos federais de segurança e informações do regime militar no Arquivo Militar. ACERVo - Revista do Arquivo Nacional, Rio de Janeiro, v. 21, n. 2, p. 29-42, jul./dez. 2008.

HERSCHMANN, Micael; RIBEIR0, Ana Paula Goulart. História da Comunicação no Brasil: um campo em construção. In: . Comunicação e História: interfaces e novas abordagens. Rio de Janeiro: Globo Universidade / Mauad X, 2008.

LAGÔA, Ana. SNI: como nasceu, como funciona. Rio de Janeiro: Brasiliense, 1983.

SODRÉ, Nelson Werneck. História da imprensa no Brasil. $4^{\mathrm{a}}$ ed. Rio de Janeiro: Mauad, 1999.

\section{Documentais:}

Fundo Instituto de Pesquisas e Estudos Sociais (IPES)

- Arquivo Nacional: 
- documento BR.AN, RIO.QL.0.CDI.37 - A ação

comunista na imprensa como peça-base à contra-

revolução programada para 1974.

Fundo Serviço Nacional de Informações (SNI) -

Arquivo Nacional:

- documento BR AN, BSB N8.0.PSN, EST.40 - Estudo

para reformulação do Conceito Estratégico Nacional.

- documento AC-ACE-93577/74-001.

- documento AC-ACE-93577/74-002.

- documento Subversivos que participaram da

Guerrilha do Araguaia.

Fundo Divisão de Segurança e Informações do MJ (DSI/

MJ): Inventário dos Processos da Série Movimentos

Contestatórios - Arquivo Nacional:

- Processo SECOM n ${ }^{0} 53.493-23 / 4 / 1971$.

- Processo SECOM n 58.611 - 2/8/1972 


\section{Epistemological contribution of the military regime to the journalistic field: the Brazilian press monograph prepared by SNI}

\section{Abstract}

From the information of major newspapers in all states of Brazil collected by branches of the National Information Service, in the documentation found in SNI Fund of the National Archive, the article conceives a monograph of the Brazilian press, emphasizing confluences, deviations and differences between communication companies and military government, in the intention of making a contribution to the studies of journalistic memory during the military regime and amplify the research sites of national expression of History of Communication in Brazil, commonly restricted to the regions Southeast and South of the country.

\section{Keywords}

Brazilian press. Newspapers. SNI. Monograph. Military regime.

\section{Contribución epistemológica del} régimen militar al campo periodístico: la monografía de la prensa brasileña desarrollada por SNI

\section{Resumen}

A partir de la información de los periódicos más importantes en todos los estados de Brasil recogidos por el Servicio Nacional de Información en la documentación que se encuentra en el Fondo SNI de lo Archivo Nacional, el artículo concibe una monografía de la prensa brasileña, destacando confluencias, desvíos y desacuerdos entre las compañías de medios y el gobierno militar, a fin de contribuir a los estudios de la memoria periodística durante el régimen militar y ampliar los sitios de búsqueda de expresión nacional de Comunicación de la historia de Brasil, habitualmente restringidos a Sudeste y Sur.

\section{Palabras clave}

Prensa brasileña. Periódicos. SNI. Monografía. Régimen militar. 


\section{Expediente}

A revista E-Compós é a publicação científica em formato eletrônico da Associação Nacional dos Programas de Pós-Graduação em Comunicação (Compós). Lançada em 2004, tem como principal finalidade difundir a produção acadêmica de pesquisadores da área de Comunicação, inseridos em instituições do Brasil e do exterior.

\section{E-COMPÓS I www.e-compos.org.br I E-ISSN 1808-2599}

Revista da Associação Nacional dos Programas de Pós-Graduação em Comunicação.

Brasília, v.18, n.3, set./dez. 2015.

A identificação das edições, a partir de 2008, passa a ser volume anual com três números.

Indexada por Latindex I www.latindex.unam.mx

\section{CONSELHO EDITORIAL}

Alexandre Farbiarz, Universidade Federal Fluminense, Brasil Alexandre Rocha da Silva, Universidade Federal do Rio Grande do Sul, Brasil Ana Carolina Damboriarena Escosteguy, Pontifícia Universidade Católica do Rio Grande do Sul, Brasil

Ana Carolina Rocha Pessôa Temer, Universidade Federal de Goiás, Brasil Ana Regina Barros Rego Leal, Universidade Federal do Piauí, Brasil Andrea França, Pontifícia Universidade Católica do Rio de Janeiro, Brasil André Luiz Martins Lemos, Universidade Federal da Bahia, Brasil Antonio Carlos Hohlfeldt, Pontifícia Universidade Católica do Rio Grande do Sul, Brasil

Arthur Ituassu, Pontifícia Universidade Católica do Rio de Janeiro, Brasil Álvaro Larangeira, Universidade Tuiuti do Paraná, Brasil Ângela Freire Prysthon, Universidade Federal de Pernambuco, Brasil César Geraldo Guimarães, Universidade Federal de Minas Gerais, Brasil Cláudio Novaes Pinto Coelho, Faculdade Cásper Líbero, Brasil Daisi Irmgard Vogel, Universidade Federal de Santa Catarina, Brasil Denize Correa Araujo, Universidade Tuiuti do Paraná, Brasil Eduardo Antonio de Jesus, Pontifícia Universidade Católica de Minas Gerais, Brasil

Daniela Zanetti, Universidade Federal do Espirito Santo, Brasil Eduardo Vicente, Universidade de São Paulo, Brasil Elizabeth Moraes Gonçalves, Universidade Metodista de São Paulo, Brasil Erick Felinto de Oliveira, Universidade do Estado do Rio de Janeiro, Brasil Francisco Elinaldo Teixeira, Universidade Estadual de Campinas, Brasil Francisco Paulo Jamil Almeida Marques, Universidade Federal do Paraná, Brasil

Gabriela Reinaldo, Universidade Federal do Ceará, Brasil Goiamérico Felício Carneiro Santos, Universidade Federal de Goiás, Brasil Gustavo Daudt Fischer, Universidade do Vale do Rio dos Sinos, Brasil Herom Vargas, Universidade Municipal de São Caetano do Sul, Brasil Itania Maria Mota Gomes, Universidade Federal da Bahia, Brasil
Janice Caiafa, Universidade Federal do Rio de Janeiro, Brasil Jiani Adriana Bonin, Universidade do Vale do Rio dos Sinos, Brasil José Afonso da Silva Junior, Universidade Federal de Pernambuco, Brasil José Luiz Aidar Prado, Pontifícia Universidade Católica de São Paulo, Brasil Juçara Gorski Brittes, Universidade Federal de Ouro Preto, Brasil Kati Caetano, Universidade Tuiuti do Paraná, Brasil

Lilian Cristina Monteiro França, Universidade Federal de Sergipe, Brasil Liziane Soares Guazina, Universidade de Brasília, Brasil Luíza Mônica Assis da Silva, Universidade de Caxias do Sul, Brasil Luciana Miranda Costa, Universidade Federal do Pará, Brasil Malena Segura Contrera, Universidade Paulista, Brasil Maria Ogécia Drigo, Universidade de Sorocaba, Brasil Maria Ataide Malcher, Universidade Federal do Pará, Brasil Marcia Tondato, Escola Superior de Propaganda e Marketing, Brasil Marcel Vieira Barreto Silva, Universidade Federal da Paraíba, Brasil Maria Clotilde Perez Rodrigues, Universidade de São Paulo, Brasil Maria das Graças Pinto Coelho, Universidade Federal do Rio Grande do Norte, Brasil

Mauricio Ribeiro da Silva, Universidade Paulista, Brasil

Mauro de Souza Ventura, Universidade Estadual Paulista, Brasil Márcio Souza Gonçalves, Universidade do Estado do Rio de Janeiro, Brasil Micael Maiolino Herschmann, Universidade Federal do Rio de Janeiro, Brasil Mirna Feitoza Pereira, Universidade Federal do Amazonas, Brasil Nísia Martins Rosario, Universidade Federal do Rio Grande do Sul, Brasil Potiguara Mendes Silveira Jr, Universidade Federal de Juiz de Fora, Brasil Regiane Regina Ribeiro, Universidade Federal do Paraná, Brasil Rogério Ferraraz, Universidade Anhembi Morumbi, Brasil Rose Melo Rocha, Escola Superior de Propaganda e Marketing, Brasil Rozinaldo Antonio Miani, Universidade Estadual de Londrina, Brasil Sérgio Luiz Gadini, Universidade Estadual de Ponta Grossa, Brasil Simone Maria Andrade Pereira de Sá, Universidade Federal Fluminense, Brasil Veneza Mayora Ronsini, Universidade Federal de Santa Maria, Brasil Walmir Albuquerque Barbosa, Universidade Federal do Amazonas, Brasil

\section{COMISSÃO EDITORIAL}

Cristiane Freitas Gutfreind

Pontifícia Universidade Católica do Rio Grande do Sul, Brasil

Irene Machado

Universidade de São Paulo, Brasil

\section{CONSULTORES AD HOC}

Claudia Peixoto de Moura, Pontificia Universidade Católica do Rio Grande do Sul, Brasil Francisco Rüdiger, Pontifícia Universidade Católica do Rio Grande do Sul, Brasil Juremir Machado da Silva, Pontifícia Universidade Católica do Rio Grande do Sul, Brasil Maria Aparecida Baccega, Universidade de São Paulo, Brasil

Roberto Tietzmann, Pontifícia Universidade Católica do Rio Grande do Sul, Brasil

\section{EQUIPE TÉCNICA}

ASSISTENTE EDITORIAL I Márcio Zanetti Negrini

REVISÃO DE TEXTOS I Press Revisão

EDITORAÇÃO ELETRÔNICA I Roka Estúdio

CONTATO I revistaecompos@gmail.com
COMPÓS I www.compos.org.br

Associação Nacional dos Programas de Pós-Graduação em Comunicação

Presidente

Edson Fernando Dalmonte

Programa de Pós-Graduação em Comunicação

e Cultura Contemporânea - UFBA

edsondalmonte@uol.com.br

Vice-presidente

Cristiane Freitas Gutfreind

Programa de Pós-Graduação em Comunicação Social - PUC-RS cristianefreitas@pucrs.br

Secretário-Geral

Rogério Ferraraz

Programa de Pós-Graduação em Comunicação

Universidade Anhembi Morumbi

rogerioferraraz@anhembimorumbi.edu.br 